\title{
Peningkatan Daya Ingat Peserta Didik Melalui Strategi Pembelajaran True Or False Pada Pembelajaran Tematik Kelas III MI Nurul Huda Cigentur
}

\author{
Dila Nurlaila Zannah ${ }^{1}$, Asis Saefuddin ${ }^{2}$, Alvin Yanuar Rahman ${ }^{3}$ \\ 1,2,3Jurusan PGMI UIN Sunan Gunung Djati Bandung, ${ }^{1}$ dilazannah98@gmail.com; \\ 2asissaefuddin@uinsgd.ac.id; 3alvinyanuar@uinsgd.ac.id
}

\begin{abstract}
Abstrak. Penelitian ini bertujuan untuk mengetahui seberapa besar peningkatan daya ingat peserta didik setelah proses pembelajaran tematik menggunakan strategi pembelajaran true or false kelas III MI Nurul Huda Cigentur. Jenis penelitian ini adalah kuasi eksperimen tipe one group peretst and posttest design. Teknik pengumpulan data dilakukan dengan penyebaran angket dan tes uraian pretest dan posttest. Jenis data penelitian ini adalah data kuantitatif yang kemudian diolah dengan uji statistik. Berdasarkan hasil penelitian pada peserta didik kelas III MI Nurul Huda Cigentur yang telah dilaksanakan, 96\% peserta didik dapat menerima materi yang dibelajarkan. Hasil pretest didapatkan nilai rata-rata sebesar 42,65, hal ini menunjukkan kurangnya pengetahuan peserta didik mengenai materi yang akan dibelajarkan sementara hasil posttest mendapatkan nilai rata-rata sebesar 79,12 menunjukkan peserta didik memiliki pengetahuan materi yang baik. Hasil analisis N-Gain menunjukkan peserta didik memperoleh peningkatan daya ingat sejumlah $66,94 \%$ yang berarti peningkatan daya ingat peserta didik yang telah mengikuti pembelajaran tematik menggunakan strategi pembelajaran true or false dikategorikan sedang.
\end{abstract}

Kata kunci: Daya ingat, Strategi Pembelajaran True or False, Pembelajaran Tematik

\begin{abstract}
This research aims to find out how much the increase in students' memory after the thematic learning process with true or false learning strategies in class III MI Nurul Huda Cigentur. This type of research is a quasi experimental type one group pretest and posttest design. Data collection techniques were carried out by distributing questionnaires and pretest and posttest description tests. This type of research data is quantitative data which is then processed by statistical tests. Based on the results of research on class III MI Nurul Huda Cigentur students that have been implemented, 96\% of students can receive the material being learned. Pretest results obtained an average value of 42.65 , this shows the lack of knowledge of students about the material to be learned while the posttest results get an average value of 79.12 shows students have good material knowledge. The results of the N-Gain analysis show that students get an increase in memory amounting to $66.94 \%$, which means an increase in the memory of students who have participated in thematic learning using a true or false learning strategy is categorized as moderate.
\end{abstract}

Keywords: Memory, True or False Learning Strategy, Thematic Learning

\section{Pendahuluan}

Indonesia merupakan negara kepulauan yang termasuk kedalam golongan negara berkembang. Programme for International Student Assesment (PISA) mengurutkan peringkat kualitas pendidikan dari berbagai negara di dunia dan Indonesia berhasil menempati urutan ke-72 dari 77 negara. Pencapaian Indonesia di urutan 5 terkahir itu menunjukkan bahwa kualitas pendidikan di Indonesia begitu buruk. 
Pengamatan secara pribadi, peringkat kualitas pendidikan di Indonesia diakibatkan tidak meratanya kualitas sekolah atau madrasah di Indonesia. Sekolah atau madrasah berbayar, biasanya memiliki outout dan sistem pelaksanaan pendidikan yang baik. Hal itu tentu dipengaruhi dari berbagai komponen pendidikan lembaga itu sendiri. Baik itu sarana dan prasarana, kurikulum dan kualitas tenaga pendidik itu sendiri.

Dalam hal sarana dan prasarana, masih banyak sekolah atau madrasah yang masuk kategori rendah. Hal tersebut salah satunya diakibatkan kurang terampilnya kepala sekolah mengatur jalannya proses pendidikan. Kurikulum 2013 dengan pembelajaran tematik yang berlaku saat ini menjadi hal yang sulit dimengerti apalagi diterapkan oleh pendidik dan pelaksanaan pembelajarannya tidak efektif pun menjadi alasan kurang baiknya kualitas pendidikan di suatu lembaga. Pelaksanaan pembelajaran yang kurang efektif tersebut terlihat dari sisi kompetensi peserta didik yang tidak tercapai secara maksimal, bahkan banyak peserta didik yang tidak mampu mengingat materi pembelajaran. Hal itu disebabkan kurang terampilnya pendidik memodifikasi pembelajaran untuk memberikan pengalaman belajar atau aktivitas peserta didik.

Padahal pelaksanaan kurikulum dalam pembelajaran adalah arah jalan terbaik untuk meningkatkan kompetensi dan ingatan materi pembelajaran peserta didik. Pembelajaran yang baik ialah pelajaran yang mampu meningkatkan kompetensi setiap peserta didik dan membuatnya mengingat berbagai kegiatan dan materi yang diajarkan selama pembelajaran. Hal tersebut bisa didapatkan dengan membuat peserta didik beraktivitas selama pembelajaran dan merasa senang saat proses belajar berlangsung, hal itu dimaksudkan agar mendapatkan pengalaman yang bermakna selama berkegiatan.

Pengalaman yang bermakna itu akan membantu peserta didik mengingat berbagai kegiatan yang dilakukan dan materi yang dibelajarkan. Sehingga. Pentingnya mengingat materi ialah agar peserta didik lebih siap menerima pembelajaran di tahap selanjutnya dan hal itu secara otomatis meningkatkan kompetensinya dari berbagai aspek.

Perlu adanya terobosan baru dalam pembelajaran agar peserta didik mendapatkan pengalaman bermakna selama aktivitas belajar dan peningkatan daya ingat setelah proses pembelajaran. Salah satu strategi pembelajara aktif yang mampu memberikan pembelajaran yang bermakna 
serta ingatan materi pelajaran yang baik adalah strategi pembelajaran aktif True or False.

Strategi True or False (Anitah, 2012) merupakan salah satu strategi dalam pembelajaran aktif yang berguna sebagai stimultan keikutsertaan peserta didik saat menerima pelajaran yang diajarkan. Strategi pembelajaran True or False memiliki tahapan-tahapan berikut (Silberman, 2017) :

a. Menyusun pernyataan mengenai materi sejumlah peserta didik. Pernyataan dibuat pernyataan benar dan pernyataan salah dengan jumlah yang seimbang.

b. Pernyataan dituliskan dalam kartu True or False (Jika jumlah siswa ganjil, pendidik boleh mengikuti kegiatan pembelajaran).

c. Kartu True or False dibagikan kepada setiap peserta didik dan meminta mereka untuk memahami pernyataan untuk menentukan kartu berjenis benar atau salah pernyataan tersebut. Peserta diberi kebebasan untuk mencari argumen penentuan jenis kartu.

d. Peserta didik memiliki kebebasan menggunakan berbagai metode yang diinginkan untuk mencari kebenaran pernyataan berikut.

e. Ketika kegiatan mencari kebenaran selesai, setiap peserta didik diberi kesempatan membaca pernyataan kartunya dengan diiringi argumen deskripsi benar atau salah.

f. Pendidik memberikan tanggapan membangun konstruk yang benar serta menganalisis perkembangan kerjasama pertim.

g. Tunjukkan bahwa keterampilan kerjasama tim yang positif sangat penting dilakukan untuk menambah keterampilan.

h. Peserta didik diarahkan oleh pendidik untuk menyimpulkan materi serta proses belajar yang sudah dilakukan.

Strategi pembelajaran aktif True or False mempunyai keunggulan yaitu menstimulus peserta didik untuk beraktivitas, membuat peserta didik senang belajar dan mendapatkan pengalaman yang bermakna untuk ingatan yang lebih lama. Kekuatan seseorang menyimpan ingatan atau sering disebut daya ingat merupakan kegiatan mengecamkan, menyimpan dan memproduksi kesan kesan pengalaman secara rohaniah. Proses mengingat juga terdiri dari tahapan menerima, menyimpan dan mereproduksi (Rahman, 2012). Jadi, daya ingat merupakan kemampuan seseorang menerima, menyimpan dan mengemukakan kembali informasi yang terdapat dalam memori. Dari pengertian tersebut, indikator daya ingat yang baik adalah seseorang mampu menerima dengan baik sebuah informasi serta mengemukakan kembali baik itu secara visual, audio dan/atau psikomotorik. 
Dalam strategi True or False setelah peserta didik mencari kebenaran dari sebuah kalimat, tanpa sengaja, dia akan menerima informasi sebanyak mungkin lalu informasi tersebut dikemukakan pada saat presentasi. Hal ini menunjukkan strategi True or False melatih daya ingat peserta didik.

Strategi True or False sudah banyak dikenali pendidik masa kini. Banyak penelitian yang sudah menunjukkan bahwa Strategi True or False mampu meningkatkan kompetensi dan daya ingat peserta didik. Oleh sebab itu, peneliti melaksanakan penelitian yang bertujuan untuk mengetahui seberapa besar peningkatan daya ingat peserta didik setelah belajar menggunakan strategi pembelajaran aktif True or False pada pembelajaran tematik kelas III di MI Nurul Huda Cigentur.

\section{Metode}

Metode yang digunakanan dalam penelitian ini adalah metode kuasi ekperimen tipe one group pretest and posttest design. Penelitian ini dilakukan dengan memberikan pretest diawal pembelajaran sebelum pemberian perlakuan dan diberikan posttest setelah seluruh pembelajaran selesai. Penelitian kuasi ekperimen tipe one group pretest and posttest design merupakan penelitian yang bertujuan untuk melihat secara akurat pengaruh perlakuan terhadap variabel yang diteliti sesuai perbandingan hasil pretest dan posttest (Sugiyono, 2008).

Jenis data dalam penelitian ini adalah data kuantitatif dengan sumber data primer langsung dari peserta didik. Populasi dalam penelitian merupakan peserta didik kelas III A MI Nurul Huda Cigentur yang berjumlah 30 orang. Teknik pengumpulan data menggunakan angket dan tes uraian.

Sebelum pretest dan posttest diberikan kepada populasi yang diteliti, peneliti menguji tingkat kesukaran, daya pembeda, validitas dan reliabilitas soal. Uji coba soal tersebut dilakukan di kelas IV B MI Nurul Huda Cigentur yang berjumlah 29 peserta didik.

Analisis penelitian meliputi uji normalitas, uji homogenitas dan uji Man Whitney untuk mengetahui perbedaan dari data pretest dan posttest. Sementara untuk mengetahui peningkatan data pretest dan posttest dilakukan dengan perhitungan peningkatan N-Gain.

\section{Hasil dan Pembahasan}

1. Uji Coba soal

Hasil uji coba soal kemudian dianalisis untuk mengetahui kelayakan soal untuk dijadikan instrumen. Berikut hasil uji tingkat kesukaran : 
Tabel 1. Tingkat Kesukaraan Soal

\begin{tabular}{ccccc}
\hline $\begin{array}{c}\text { Butir } \\
\text { Soal }\end{array}$ & $\begin{array}{c}\text { Jumlah } \\
\text { Peserta } \\
\text { didik }\end{array}$ & $\begin{array}{c}\text { Banyaknya peserta } \\
\text { didik yang menjawab } \\
\text { soal dengan benar }\end{array}$ & $\begin{array}{c}\text { Tingkat } \\
\text { Kesukaran }\end{array}$ & Interpretasi \\
\hline 1 & 29 & 106 & 0,37 & Sedang \\
2 & 29 & 95 & 0,33 & Sedang \\
\hline
\end{tabular}

Interpretasi dari kedua soal memiliki tingkat kesukaran yang sedang. Selanjutnya, pengujian daya pembeda soal didapatkan hasil berikut.

Tabel 2. Daya Pembeda Soal

\begin{tabular}{lc|c}
\hline \multicolumn{1}{c|}{ Butir Soal } & 1 & 2 \\
\hline Banyak skor benar kelompok atas & 58 & 63 \\
Banyak skor benar kelompok bawah & 44 & 29 \\
Skor maksimum & \multicolumn{2}{|c}{5} \\
Jumlah peserta didik kelompok atas/bawah & \multicolumn{2}{|c}{14} \\
Daya Pembeda & 0,20 & 0,49 \\
Interpretasi & Cukup & Baik \\
\hline
\end{tabular}

Hasil analisis menunjukkan kedua soal instrumen tersebut mampu menjadi pembeda peserta didik selama penelitian. Selanjutnya, menguji validitas intrumen soal. Berikut hasil perhitungan pengujian validitas.

Tabel 3. Uji Validitas Soal

\begin{tabular}{c|c|c}
\hline \multirow{2}{*}{ Aspek Yang Dihitung } & \multicolumn{2}{|c}{ Butir Soal } \\
\cline { 2 - 3 } & 1 & 2 \\
\hline $\mathrm{N} \cdot \sum \mathrm{XY}-\left(\sum \mathrm{X}\right)\left(\sum \mathrm{Y}\right)$ & 1865 & 2365 \\
\hline$\sqrt{\left(\left(\mathrm{N} \cdot \sum \mathrm{X}^{2}-\left(\sum \mathrm{X}\right)^{2}\right)\left(\mathrm{N} \cdot \sum \mathrm{Y}^{2}-\right.\right.}$ & & 2840,92 \\
$\left.\left.\left(\sum \mathrm{Y}\right)^{2}\right)\right)$ & 2440,46 & 0,83 \\
\hline Validitas & 0,76 & Sangat tinggi/sangat kuat \\
\hline Interpretasi & Tinggi/kuat
\end{tabular}

Hasil analisis diatas menunjukkan bahwa soal pertama $(r=0,76)$ memiliki interpretasi tingkat validitas yang tinggi. Sementara pada soal kedua ( $\mathrm{r}=$ 0,83 ) memiliki interpretasi tingkat kesesuaian yang sangat tinggi. Selanjutnya, peneliti menguji reabilitas instrumen yang berfungsi untuk mengetahui tingkat ketetapan instrumen. Uji reabilitas ini menggunakan teknik Alfa-Cronbrach karena soal yang diujikan merupakan soal uraian. Berikut hasil perhitungan pengujian reabilitas. 
Tabel 4 Uji Reliabilitas Soal

\begin{tabular}{ll}
\hline & Skor \\
\hline Jumlah varians tiap soal & 4,08 \\
varians total & 5,21 \\
Reabilitas & 0,43 \\
Interpretasi & Reabilitas sedang \\
\hline
\end{tabular}

Analisis data tersebut menunjukkan bahwa reabilitas soal yang diujikan ( $\mathrm{r}_{\mathrm{i}}$ $=0,43)$ memiliki tingkat ketetapan yang sedang. Diketahui $r_{i}(0,43)>r$ tabel dengan taraf signifikansi 5\% $(0,367)$ maka intrumen tes dinyatakan reliabel. Semua hasil analisis tersebut menunjukkan bahwa soal layak dijadikan instrumen penelitian.

2. Analisis Peningkatan Daya Ingat

Sebelum mengetahui peningkatan daya ingat melalui hasil pretest dan posttest, peneliti menganalisis angket yang diberikan untuk mengetahui seberapa besar peserta didik mampu menerima materi pembelajaran. Berikut hasil persensi angket.

Tabel 5. Persensi Angket

\begin{tabular}{|c|c|c|c|c|c|}
\hline & \multicolumn{3}{|c|}{ Angket } & \multirow{2}{*}{ Skor } & \multirow{2}{*}{ Nilai } \\
\hline & 1 & 2 & 3 & & \\
\hline Skor dari 34 Peserta didik (SP) & 89 & 84 & 85 & 258 & 2867 \\
\hline Skor maksimum (SM) & & 90 & & 300 & 3000 \\
\hline Persensi angket (SP : SM) & $99 \%$ & $93 \%$ & $94 \%$ & $96 \%$ & $96 \%$ \\
\hline
\end{tabular}

Analisis angket menunjukkan bahwa peserta didik di kelas kontrol mampu menerima informasi pembelajaran sebesar $96 \%$ nilai keseluruhan. Hasil tersebut menunjukkan bahwa kemampuan peserta didik menerima materi pembelajaran sangat baik. Selanjutnya peneliti menganalisis peningkatan daya ingat melalui hasil pretest dan posttest peserta didik yang hadir pada tes tersebut.

Tabel 6. Uji Normalitas Pretest dan Posttest

Kolmogorov-Smirnov ${ }^{\text {a }}$

\begin{tabular}{cccc} 
& Statistic & Df & Sig. \\
\hline Pretest & 0,307 & 30 & 0,000 \\
Posttest & 0,187 & 30 & 0,009 \\
\hline
\end{tabular}

Hasil analisis menunjukkan nilai sig pretest $(0,000)<$ nilai $\alpha(0,05)$, maka data nilai pretest berdistribusi tidak normal. Begitupula dengan nilai sig posttest $(0,009)<$ nilai $\alpha(0,05)$, maka data nilai posttest berdistribusi tidak normal. 
Selanjutnya pengujian homogenitas varians mendapatkan hasil sebagai berikut :

Tabel 7. Uji Homogenitas Pretest dan Posttest

\begin{tabular}{lrrrrr}
\hline & Levene Statistic & df1 & df2 & Sig. \\
\hline Skor & Based on Mean & 2,273 & 1 & 58 & 0,137 \\
\hline
\end{tabular}

Hasil analisis menunjukkan nilai sig kelas eksperimen $(0,137)>$ nilai $\alpha(0,05)$, maka data nilai pretest dan posttest memiliki varians yang homogen. Selanjutnya untuk mengetahui peningkatan daya ingat peserta didik, analisis hipotesis terdapat perbedaan sebelum dan sudah pembelajaran dilakukan dengan uji Man-Whitney karena kedua data berdistribusi tidak normal.

Tabel 8. Uji Man Whitney Pretest dan Posttest

\begin{tabular}{lr}
\hline & \multicolumn{1}{c}{ Skor } \\
\hline Mann-Whitney U & 49,000 \\
Wilcoxon W & 514,000 \\
Z & $-6,025$ \\
Asymp. Sig. (2-tailed) & 0,000 \\
\hline
\end{tabular}

Didapatkan Asymp. Sig. (2-tailed) $(0,000)<$ nilai probabilitas $(0,05)$, maka terdapat perbedaan daya ingat peserta didik sebelum dan sesudah pembelajaran Tematik meggunakan strategi True Or False. Selanjutnya untuk mengetahui peningkatan daya ingat dilakukan dengan perhitungan N-Gain sebagai berikut.

\begin{tabular}{lll}
\multicolumn{3}{c}{ Tabel 9 N-Gain Peningkatan Daya Ingat } \\
\hline \multicolumn{1}{c}{ Kelas } & \multicolumn{1}{c}{ Statistic } & Std. Error \\
\hline Mean & $66,94 \%$ & 5,836 \\
95\% Confidence Interval for Mean & Lower Bound & 55,01 \\
& Upper Bound & 78,88 \\
5\% Trimmed Mean & & 68,83 \\
Median & 73,21 \\
\hline
\end{tabular}

Hasil mean statistic menunjukkan peningkatan pengetahuan sebesar $66,94 \%$. Jadi, daya ingat peserta didik setelah mengikuti pembelajaran tematik menggunakan strategi Tue or False dalam kategori tafsiran efektivitas N-Gain Heke mengalami peningkatan yang dikategorikan sedang.

\section{Simpulan}

Berdasarkan hasil penelitian pada peserta didik kelas III MI Nurul Huda Cigentur yang telah dilaksanakan, $96 \%$ peserta didik dapat menerima materi 
yang dibelajarkan. Hasil pretest didapatkan nilai rata-rata sebesar 42,65, hal ini menunjukkan kurangnya pengetahuan peserta didik mengenai materi yang akan dibelajarkan sementara hasil posttest mendapatkan nilai rata-rata sebesar 79,12 menunjukkan peserta didik memiliki pengetahuan materi yang baik. Hasil analisis N-Gain menunjukkan peserta didik memperoleh peningkatan daya ingat sejumlah $66,94 \%$ yang berarti peningkatan daya ingat peserta didik yang telah mengikuti pembelajaran tematik menggunakan strategi pembelajaran true or false dikategorikan sedang.

Adapun beberapa rekomendasi dari peneliti yaitu alangkah baiknya dalam satu rombongan belajar terdiri tidak lebih dari 24 peserta didik. Selanjutnya, pendidik harus sadar akan kewajibannya, memperluas wawasan pendidikan dan lebih inovatif dalam melaksanakan pembelajaran. Inovasi dalam pembelajaran dimaksudkan agar peserta didik mendapatkan pengalaman bermakna pada saat pembelajaran agar memiliki daya ingat yang baik.

\section{Daftar Pustaka}

Anitah. (2012). Media Pembelajaran. Surakarta.

Bungin, B. (2011). Metodologi Penelitian Kuantitatif. Jakarta: Kencana Prenada Media Group.

Rahayu, Y. N. (2018). Statistika pendidikan. Bandung.

Rahman, A. (2012). Keefektifan Pembelajaran dengan Pendekatan Pendidikan Matematika Realistik Indonesia Ditinjau dari Pencapaian Kemampuan Pemecahan Masalah Matematik dan Karakter Peserta didik SMP. Jurnal UNY.

Silberman, M. (2017). Active Learning 101 Cara Peserta Didik Belajar Aktif. Bandung: Nuansa Cendikia.

Sugiono. (2014). Statistika untuk Penelitian. Bandung: CV. ALFABETA.

Sugiyono. (2008). Metode Penelitian Pendidikan (Penelitian Kuantitatif, Kualitatif dan RED) . Bandung: Alfabeta. 